D.O.I.: $10.3895 / \mathrm{S} 1808-04482006000400002$

\title{
SISTEMA DA GESTÃO DA RESPONSABILIDADE SOCIAL: DESAFIOS PARA A CERTIFICAÇÃO NBR 16001
}

\section{SOCIAL RESPONSIBILITY MANAGEMENT SYSTEM: CHALLENGES FOR THE NBR 16001 CERTIFICATION}

\author{
Alexandre Nixon Soratto ${ }^{1}$; Antônio Augusto Morini ${ }^{2}$; Márcia Andréia S. Almeida ${ }^{3}$; \\ Patrícia de Souza Knabben ${ }^{4}$; Gregorio Varvakis ${ }^{5}$ \\ ${ }^{1}$ Federal University of Santa Catarina - UFSC/EGC - Florianópolis - Brasil \\ ansoratto@inmetro-sc.gov.br \\ ${ }^{2}$ Federal University of Santa Catarina - UFSC/EGC - Florianópolis - Brasil \\ morini@,cwb.matrix.com.br \\ ${ }^{3}$ National Institute of Metrology, Standization and Industrial Quality - Inmetro - RJ - Brasil \\ msalmeida@inmetro.gov.br \\ ${ }^{4}$ Estácio de Sá University - Florianópolis - Brasil \\ patisk@gmail.com \\ ${ }^{5}$ Federal University of Santa Catarina - UFSC/EGC - Florianópolis - Brasil \\ grego@egc.ufsc.br
}

\begin{abstract}
Resumo
Este artigo discute a avaliação da conformidade e a certificação de sistema da gestão da responsabilidade social, de acordo com a ABNT NBR 16001:2004. Pelo entendimento dos princípios da certificação e das boas práticas de responsabilidade social empresarial são avaliados requisitos da referida norma e levantadas as dificuldades de se evidenciar a conformidade durante a auditoria. Atenção para a composição e a competência da equipe auditora e a elaboração de diretrizes para a interpretação da norma, são propostas que têm como objetivo minimizar as diferenças nos critérios dos auditores e maximizar a efetividade na constatação da conformidade de sistemas da gestão da responsabilidade social organizacional. Essas sugestões contribuem para aumentar a confiabilidade e a credibilidade do processo de certificação, fazendo com que as empresas comprometidas com o desenvolvimento sustentável, possam melhor avaliar e demonstrar às partes interessadas, suas práticas de responsabilidade social.
\end{abstract}

Palavras-chave: responsabilidade social; certificação; sistema de gestão.

\section{Introdução}

Muito debatida no meio acadêmico e empresarial, a responsabilidade social vem se tornando, em muitos casos, um referencial de excelência para o mundo dos negócios, sob a perspectiva de um modelo de desenvolvimento sustentável, que resulta da harmonia entre as dimensões econômica, social e ambiental. 
Esse novo modelo de gestão desencadeou uma série de iniciativas, discussões e atitudes que deslocaram o foco da exploração para a preservação, impondo aos humanos o desafio de tornar a vida no planeta não apenas viável no presente, mas também no futuro.

No âmbito empresarial, a responsabilidade social é o conceito que alinha o comportamento das organizações às perspectivas da sustentabilidade. E é seguindo essa tendência que os trabalhos de Ursini e Sekiguchi (2005), Instituto Ethos (2005), Sirgy (2002), McWillians e Siegel (2001) apontam para a importância de se discutir a temática nesse novo contexto.

A responsabilidade social corporativa (RSC) ou empresarial (RSE) evolui a cada dia acompanhando a mudança do pensamento social sobre a manutenção da vida. Consumidores mais exigentes, empresas comprometidas com valores éticos universais, como o respeito aos direitos humanos, compõem uma combinação que vem transformado sociedades e colocado em questão padrões de produção e consumo que inviabilizam a vida no planeta (CAPRA, 2002).

No que tange ao desenvolvimento das práticas voltadas à responsabilidade social corporativa, estas têm sido, significativamente, influenciadas pela evolução da normalização em sistemas da gestão empresarial, que por sua vez, vem possibilitado avaliar a conformidade do Sistema da Gestão da Responsabilidade Social - SGRS.

E nesse sentido, as normas SA 8000 e a AA 1000 têm sido referências para organizações de todo o mundo.

Seguindo essa tendência, em 2004, a Associação Brasileira de Normas Técnicas - ABNT editou a NBR 16001, primeiro documento normativo a estabelecer requisitos para Sistema da Gestão da Responsabilidade Social e principal referência para a certificação desse tipo de sistema de gestão, no âmbito do Sistema Brasileiro de Avaliação da Conformidade - SBAC.

A ABNT NBR 16001:2004 reúne um conjunto de requisitos associados à ética, cidadania, direitos humanos e desenvolvimento sustentável e foi elaborada de modo a ser aplicável a todos os tipos e portes de organizações ajustando-se às diferentes condições geográficas, culturais e sociais do país.

No entanto, a tentativa de tornar a norma abrangente e flexível ao ponto de moldar-se aos diversos tipos e portes de organizações, acentuou aspectos de generalidade que associados à subjetividade de seus requisitos e à necessidade do envolvimento de partes externas à organização, tornaram-na uma norma, cuja certificação é mais complexa e diferenciada que a dos demais sistemas de gestão normalizados, como os da qualidade, ambiental e de saúde e segurança.

Tais características têm favorecido e valorizado o surgimento de pesquisas que buscam a melhor interpretação de seus requisitos, bem como a identificação das boas práticas de auditoria da certificação de SGRS. 
Nesse contexto, este trabalho objetiva identificar e discutir as especificidades e a complexidade da certificação de Sistema da Gestão da Responsabilidade Social, com base na ABNT NBR 16001:2004 e no âmbito do SBAC.

Inicia com uma breve explanação conceitual sobre normalização e certificação de sistemas de gestão, apresenta os princípios da referida norma e discute suas especificações para a responsabilidade social corporativa ou empresarial, apontando as dificuldades de se evidenciar a conformidade em auditoria de certificação, finalizando com propostas que objetivam assegurar competência e confiança aos processos de certificação de SGRS.

\section{Normalização e certificação voltada à responsabilidade social}

Para fins deste trabalho e com base no ISO/IEC Guide 2 (2004), a certificação deve ser entendida como o modo pelo qual uma terceira parte, independente, provê garantia escrita de que um determinado sistema de gestão está em conformidade com os requisitos, que geralmente são especificados em normas de referência. Esse conceito justifica a importância da normalização para a certificação de sistemas de gestão, no âmbito do SBAC.

No Brasil, a certificação de sistemas de gestão normalizados é concedida por Organismos Certificadores, cuja competência técnica é reconhecida pelo Instituto Nacional de Metrologia, Normalização e Qualidade Industrial (INMETRO), que por sua vez é o gestor do Sistema Brasileiro de Avaliação da Conformidade - SBAC (INMETRO, 2004).

Vários são os tipos sistemas de gestão organizacionais e muitas são as normas, nacionais e internacionais, utilizadas como referência em processos de implementação e de certificação desses sistemas. Entretanto, ao se realizar uma análise histórica percebe-se, conforme mostra a Figura 1, uma clara tendência na evolução e disseminação dos sistemas de gestão. Questões como sustentabilidade e responsabilidade social passam a receber mais atenção, principalmente de organizações mais competitivas. 


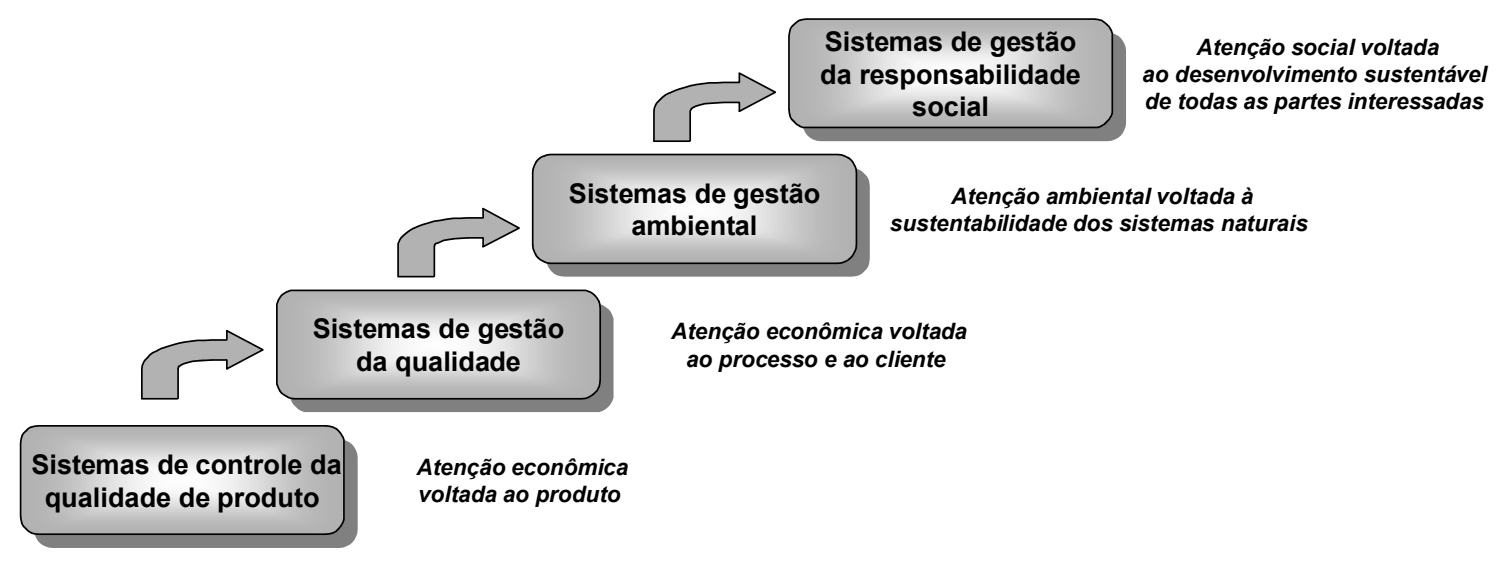

Fonte: Elaborado pelos autores.

Acompanhando essa tendência, algumas normas conquistaram seu espaço, especificando diretrizes para a gestão da responsabilidade social nas organizações.

A norma internacional mais conhecida, atualmente, é a SA 8000, publicada em 1997 pela entidade americana Social Accountability International. Seu foco está na responsabilidade das organizações para com as relações com seus trabalhadores, com base nos direitos humanos postulados pela Organização Internacional do Trabalho (OIT).

Outra norma muito conhecida é a AA 1000, cuja primeira versão foi introduzida em 1999 pela entidade britânica Institute of Social and Ethical AccountAbility. Essa norma não é certificável e busca o comprometimento das organizações para com as partes interessadas, vinculando as questões sociais e éticas à gestão estratégica e às operações da empresa.

A elaboração de normas para a gestão da responsabilidade social é uma tarefa complexa, pois envolve questões como ética e cultura, o que dificulta a obtenção do consenso dos requisitos, principalmente, em nível internacional.

Essa dificuldade vem sendo encontrada pela International Organization for Standardization (ISO) na elaboração da norma internacional ISO 26000, que propõe o estabelecimento de diretrizes para a responsabilidade social nas organizações dos países membros. Após três anos de estudo, a ISO optou por elaborar uma espécie de guia de referência para orientar as nações que desejam elaborar norma de SGRS.

Ante aos esforços de normalizar SGRS, em todo o mundo, surge a ABNT NBR 16001:2004 com o potencial de alavancar a sistematização da gestão da responsabilidade social nas organizações brasileiras e possibilitar a certificação no âmbito do SBAC. 
A certificação desse tipo de sistema no SBAC, segue o Regulamento de Avaliação da Conformidade - RAC, elaborado pelo Inmetro e aprovado em fevereiro de 2006. Nesse documento estão estabelecidos os critérios do Programa de Avaliação da Conformidade de SGRS, com base na ABNT NBR 16001:2004.

De acordo com o RAC, o processo de certificação desse tipo de sistema de gestão deve contemplar, diferentemente da avaliação dos demais tipos de sistemas de gestão, a auditoria em duas fases:

a) Auditoria fase 1: tem início com a análise crítica, pelo Organismo Certificador, da solicitação da certificação, compreendendo a análise da documentação (manual, procedimentos e instruções), a consulta prévia e divulgação às partes interessadas;

b) Auditoria fase 2: compreende a auditoria do SGRS nas instalações da organização com entrevistas com a força de trabalho da mesma para verificar o atendimento aos requisitos da norma ABNT NBR 16001:2004.

É na fase 2 da auditoria que se encontram as dificuldades potenciais para os auditores, no que diz respeito ao trabalho de constatação da conformidade do sistema de gestão

\section{ABNT NBR 16001:2004 - responsabilidade social - requisitos para sistema de gestão}

A ABNT NBR 16001:2004 estabelece uma estrutura de requisitos relativos à sistema da gestão da responsabilidade social, fundamentados na promoção da cidadania, no desenvolvimento sustentável (econômico, ambiental e social) e na transparência das atividades das organizações.

Partindo da abordagem de processos, a norma utiliza a metodologia PDCA (Plan, Do, Check, Act), conforme mostra a Figura 2, buscando facilidade para seu entendimento e aplicabilidade.

Figura 2 - Modelo do sistema de gestão da responsabilidade social

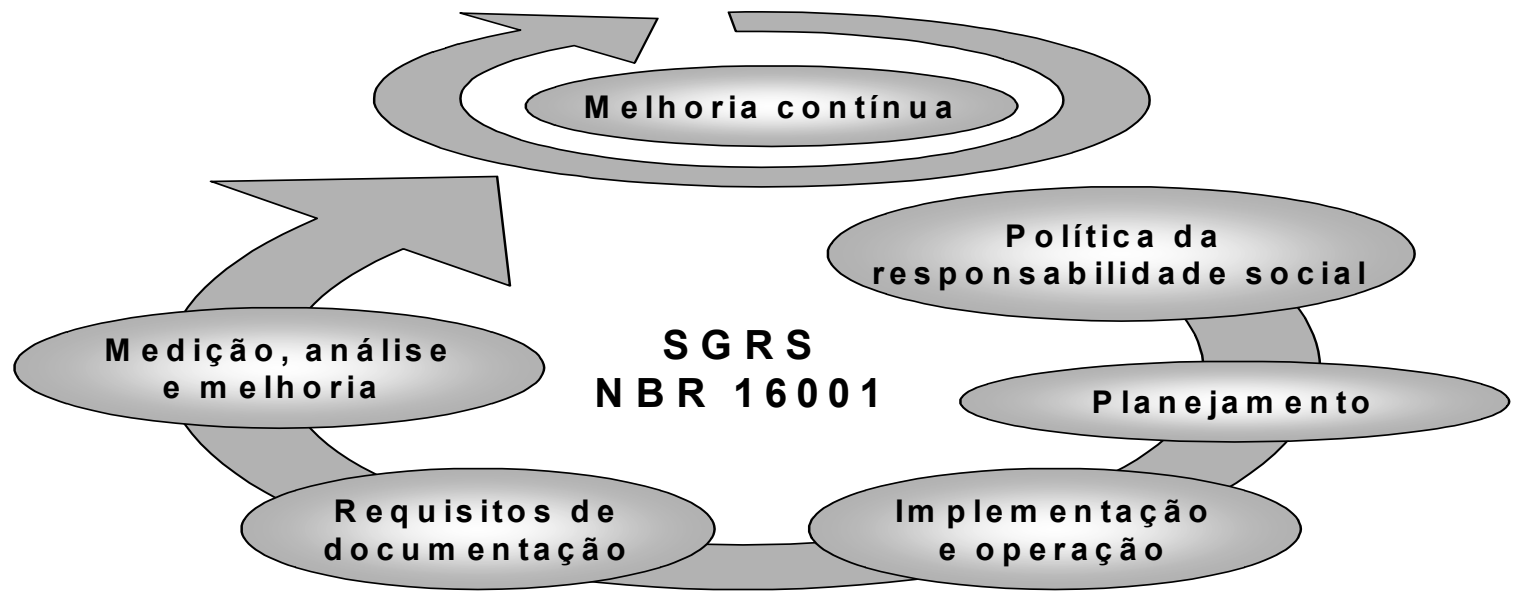

Fonte: Adaptado da ABNT NBR 16001, 2004 
Tanto sua estrutura, quanto parte do seu conteúdo se assemelham à NBR ISO 14001:2004, o que lhe confere a característica de flexibilidade, no que diz respeito a sua integração aos demais sistemas de gestão, como o da qualidade e o ambiental.

Um dos grandes diferenciais da ABNT NBR 16001:2004 está no item planejamento, que contraditoriamente pode ser considerado o ponto mais crítico da norma. No item 3.3.3, a norma menciona, de modo superficial, os objetivos, metas e programas que a organização deve contemplar na área de responsabilidade social, ressaltando que estes devem ser documentados, implementados e mantidos, tanto na organização, quanto em relação às partes interessadas.

Os objetivos e metas devem ser quantificados sempre que exeqüível e compatíveis com a política da responsabilidade social, contemplando ações vinculadas às seguintes temáticas: a) boas práticas de governança; b) combate a pirtaria, sonegação, fraude e corrupção; c) práticas leais de concorrência; d) direitos da criança e do adolescente, incluindo o combate ao trabalho infantil; e) direitos do trabalho, incluindo o de livre associação, de negociação, f) a remuneração justa e benefícios básicos, bem como o combate ao trabalho forçado; g) a promoção da diversidade e combate à discriminação (por exemplo: cultural, de gênero, de raça/etnia, idade, pessoa com deficiência); h) promoção da saúde e segurança; i) promoção de padrões sustentáveis de desenvolvimento, produção, distribuição e consumo, contemplando fornecedores, prestadores de serviço, entre outros; j) proteção ao meio ambiente e aos direito das gerações futuras; e 1) ações sociais de interesse público.

Essas temáticas são propostas pela norma sem suficiente contextualização, dando margem à livre interpretação e à identificação de outros temas pertinentes, o que, aliás, é textualmente recomendando.

Num esforço de interpretação, e considerando as de idéias de Myers (2003), Junior (2005) e Machado Filho (2006), as temáticas propostas são comentadas a seguir, tanto sob a perspectiva das organizações como das equipe auditora de SGRS.

A partir da definição de governança que consta da norma, as boas práticas de governança estão vinculadas ao modo como as organizações são dirigidas e controladas, implicando no relacionamento entre acionistas e cotistas, na existência dos conselhos fiscal e de administração, bem como na prática da auditoria independente. As boas práticas de governança devem permitir que proprietários, acionistas e cotistas tenham perfeita visibilidade da organização, considerando a prestação de contas, eqüidade e transparência.

O combate à pirataria, sonegação, fraude e corrupção é uma temática bem objetiva para as organizações, entretanto é, sem dúvida, a de maior dificuldade para a constatação dos auditores. Pressupõe que para combater esses crimes é necessário primeiramente que as organizações não os 
pratique. A auditoria pode verificar o licenciamento de softwares e outras mídias, a conscientização dos colaboradores, a ocorrência de denúncias e o histórico de problemas relacionados à sonegação, fraude e corrupção.

O culto a práticas leais de concorrência remete aos princípios da organização no que tange à prática de preços e concorrência. $\mathrm{O}$ auditor pode verificar estas práticas e se ocorreram denúncias no Conselho de Administração de Defesa Econômica (CADE)

Os direitos da criança e do adolescente, incluindo o combate ao trabalho infantil, pode ser demonstrado pela organização também por meio de: incentivo a adoção da mesma prática pelos fornecedores e outras partes interessadas, emprego de menores entre 14 e 16 anos como aprendizes e destinação de um percentual do imposto de renda devido aos fundos geridos pelos conselhos dos direitos da criança e do adolescente.

Os direitos do trabalhador, incluindo o de livre associação, de negociação, a remuneração justa e benefícios básicos, bem como o combate ao trabalho forçado estão relacionados, respectivamente, ao cumprimento da legislação vigente a respeito do trabalho de menores, à manutenção dos benefícios garantidos pela Consolidação das Leis do Trabalho - CLT, ao estímulo a livre associação, à remuneração justa e à inexistência de trabalho forçado. Evidenciar o cumprimento dessas leis vai exigir um razoável conhecimento do direito e habilidade na condução de entrevistas.

A promoção da diversidade e combate à discriminação se traduz no respeito ao indivíduo e na valorização da diversidade que está na consideração às diferenças (cultura, gênero, raça/etnia, idade, necessidades especiais), no exercício da tolerância e nas relações de parceria, que tenham como base a ética e a valorização do bem comum. O estabelecimento de estratégias de recrutamento e promoção, indicadores que demonstrem qual a real situação do quadro funcional da empresa, oferecer salários idênticos entre homens e mulheres, negros e brancos para uma mesma função e outras ações que demonstrem eqüidade devem ser consideradas.

O compromisso com o desenvolvimento profissional deve ser estendido aos diversos níveis hierárquicos da organização com a instituição de programas focados na erradicação do analfabetismo, educação básica ou ensino supletivo, especialização de técnicos e profissionais graduados e estímulo a evolução profissional de aprendizes e estagiários.

A promoção da saúde e segurança está vinculada ao cumprimento das obrigações legais vigentes e à adesão à programas que objetivem melhorar a saúde dos trabalhares. Neste tema, patamares superiores para a gestão da saúde e segurança organizacional podem ser alcançados com a certificação pela BS 8800 e OHSAS 18001, por exemplo. 
A promoção de padrões sustentáveis de desenvolvimento, produção, distribuição e consumo, contemplando fornecedores, prestadores de serviço enfoca a perspectiva do desenvolvimento sustentável que pressupõe a sustentabilidade como um processo dinâmico e que deve ser analisado a partir de uma visão sistêmica dos fenômenos que o envolvem. Essa visão, deve contemplar não apenas ações da organização relacionadas ao produto ou serviço ofertado, tais como produção, distribuição e consumo, mas também o agir no desenvolvimento de seus fornecedores e prestadores de serviço, através de transferência de conhecimento técnico e valores éticos.

A proteção ao meio ambiente e aos direitos das gerações futuras segue os mesmos postulados da sustentabilidade, exigindo que a organização demonstre seu comprometimento com o meio ambiente, entre outros, pela adesão a certificações com base em norma ambiental e promoção campanhas educativas, inclusive sobre os impactos gerados a partir de suas atividades. A organização pode desenvolver campanhas periódicas de redução de consumo de energia e de água e reciclagem de materiais ou desenvolver fóruns e debates internos sobre preservação ambiental, coleta seletiva e reciclagem de resíduos ou sobre os impactos ambientais causados por seus produtos ou serviços. As ações podem contemplar um programa de gerenciamento de resíduos, informações no produto sobre seu destino final, não utilização de materiais e insumos provenientes de exploração ilegal, contribuição para a preservação da biodiversidade e conservação de áreas protegidas e outros.

$\mathrm{E}$, por fim, as ações sociais de interesse público que podem ser direcionadas, tanto à comunidade de entorno, quanto a áreas mais abrangentes. Investimentos no desenvolvimento sócioeconômico da comunidade, geração de emprego e renda, construção de áreas comuns (parques, praças, centros comunitários) e estímulo à prática do serviço voluntário pelos funcionários, estão entre as ações possíveis.

O esforço de interpretar esses requisitos, só acentua a dificuldade de evidenciá-los nas auditorias de certificação, demonstrando que essa tarefa vai exigir um nível de competência das equipes auditoras, de forma a atender a ABNT NBR 16002:2005, principalmente no que diz respeito à compreensão da interação das relações, processos e produtos da organização auditada com o meio ambiente, contexto econômico e contexto social, tendo como referência as temáticas aqui discutidas.

A que se considerar, ainda, que a falta de detalhamento, na norma, das temáticas acima comentadas, tende não apenas a dificultar o processo de auditoria de certificação, mas a aumentar a responsabilidade do auditor no julgamento de requisitos menos qualificáveis, intangíveis e até certo ponto subjetivos. 
Essa situação pode dar margem a proliferação de critérios diferenciados entre os auditores no momento de se evidenciar a conformidade ou, o que é pior, diante da necessidade de se caracterizar uma não-conformidade. A variabilidade oriunda da interpretação dos requisitos da norma pode influenciar significativamente na consistência dos serviços de certificação oferecidos pelos diversos organismos de certificação.

Associa-se a essas dificuldades o fato da norma ressaltar que duas organizações que desenvolvam atividades similares, mas que apresentem níveis diferentes de desempenho de responsabilidade social, podem, ambas, atender aos seus requisitos. Entende-se que, mesmo que a ABNT NBR 16001 não se proponha a prescrever critérios de desempenho e que o Regulamento da Avaliação da Conformidade não faça menção a esses critérios, faz-se necessário o estabelecimento de diretrizes mais específicas para o atendimento de cada uma das temáticas comentadas, objetivando orientar as organizações e os auditores e minimizar conflitos indesejáveis, bem como discrepâncias no processo de concessão da certificação.

\section{Conclusão}

A ABNT NBR 16001:2004 surge no cenário nacional imbuída do desafio de ser a mais importante ferramenta de auxílio a sistematização da gestão da responsabilidade social no Brasil, o que torna a iniciativa da sociedade civil organizada, de elaborá-la, um marco histórico no alinhamento do discurso e práticas corporativas à tendência mundial do desenvolvimento a partir dos postulados da ética e da sustentabilidade.

Ao analisar, no âmbito do Sistema Brasileiro de Avaliação da Conformidade, as peculiaridades da certificação de sistema da gestão da responsabilidade social, conforme a ABNT NBR 16001:2004, constatou-se obstáculos potenciais à auditoria de certificação, considerando a subjetividade de seus requisitos e a dificuldade de quantificar objetivos, metas e programas, de acordo com as temáticas propostas.

Nesse sentido, e com a finalidade de minimizar discussões indesejáveis num processo de concessão da certificação e maximizar a harmonização dos critérios de auditoria, propõe-se para trabalhos futuros, a elaboração de um conjunto de orientações (diretrizes) sobre as temáticas propostas no item 3.3.3 de modo a auxiliar a interpretação de auditores, bem como das organizações que postulam a certificação. Bom seria se cada temática fosse subdividida em ações de responsabilidade social, obviamente sem a pretensão de esgotá-las. Isso facilitaria o processo de implementação da norma e a auditoria externa. 
Ursini e Sekiguchi (2005) comentam que entre os desafios enfrentados pelas iniciativas de elaboração de normas de responsabilidade social está a formação e incorporação de "auditores sociais" nas organizações, com representatividade e legitimidade junto às partes interessadas, promovendo sua participação em processos de verificação e auditorias do SGRS. E é nesse contexto, que ressalta-se a importância do cuidado com a composição da equipe auditora, que deve considerar a competência, principalmente, nas áreas associadas às ações de responsabilidade social empresarial propostas pela norma.

Outro aspecto relevante é que os conhecimentos, habilidades e atitudes dos membros da equipe auditora (auditor-líder, auditores e especialistas) devem ser complementares de modo a assegurar a consistência, coerência e boa condução dos trabalhos de avaliação da conformidade. A competência global da equipe deve ser tal, que permeie, dentre outras áreas, a sociologia, o direito, a educação e a administração.

A percepção apurada de uma equipe auditora de SGRS pode contribuir para inibir que organizações descomprometidas se apropriem do discurso da responsabilidade social de modo a se promoverem em cima de iniciativas muito limitadas ou pouco transparentes e efetivas para as partes interessadas.

Considerando que a certificação se apresenta como um mecanismo eficiente e eficaz para que as organizações demonstrem, com transparência, seus compromissos com uma conduta ética e socialmente responsável, entende-se que essas contribuições podem prover a confiança e credibilidade requeridas ao processo de certificação de SGRS, no âmbito do SBAC, do contrário, a sujetividade dos requisitos, aliada à necessidade de um novo perfil de auditor, insistirão em desafiar a consistência, coerência e confiabilidade do processo de auditoria de certificação, ameaçando a credibilidade do Programa de Avaliação da Conformidade de SGRS.

\begin{abstract}
This article discusses the conformity assessment and the certification of the social responsibility management system, in agreement with ABNT NBR 16001:2004. Through the understanding of the principles of the certification and of the good practices of corporation social responsibility, the requirements of the referred standard are evaluate and some difficulties of evidencing the conformity during the auditing are appointed. Attention for the composition and the team auditor's competence, and the elaboration of guidelines for the interpretation of the standard, are proposed as an objective to minimizes the differences in the auditors' criteria and to maximize the effectiveness in the verification of the conformity of the organizational social responsibility administration management systems. Those suggestions contribute to increase the reliability and the credibility of the certification process, doing with that the committed companies with the maintainable development, better they can evaluate and to demonstrate to the stakeholderss, their practices of social responsibility.
\end{abstract}

Key words: social responsibility; certification; management systems. 


\section{Referências}

ASSOCIAÇÃO BRASILEIRA DE NORMAS TÉCNICAS. ABNT NBR 16001. Responsabilidade social - Sistemas da gestão - Requisitos. Rio de Janeiro, 2004, 11 p.

ASSOCIAÇÃO BRASILEIRA DE NORMAS TÉCNICAS. ABNT NBR 16002. Responsabilidade social - Sistemas da gestão - Qualificação de auditores. Rio de Janeiro, 2005, 9p.

CAPRA. F. As Conexões Ocultas: Ciência para uma vida sustentável. São Paulo: Cultrix, 2002.

INMETRO. Portaria n. ${ }^{\circ}$ 27/2006. Aprova o Regulamento de Avaliação da Conformidade para Sistema de Gestão da Responsabilidade Social com base na Norma ABNT NBR 16001:2004. 2006. Disponível em: $<$ http://www.inmetro.gov.br>. Acesso em: 25.04.2006.

INMETRO. Cartilha da Avaliação da Conformidade. Elaborada pela Diretoria de Qualidade, 2004. Disponível $\mathrm{em}:<\mathrm{http}: / /$ www.inmetro.gov.br>. Acesso em: 12.01.2006.

INSTITUTE OF SOCIAL AND ETHICAL ACCOUNTABILITY. Disponível em: $<$ http://www.accountability.org.uk/>. Acesso em: 17.05.2006.

INSTITUTO ETHOS. Indicadores Ethos de Responsabilidade Social Empresarial, 2005. 80p. Disponível em: <htpp://www.ethos.org.br>. Acesso em: 20.03.2006.

INTERNATIONAL ORGANIZATION FOR STANDARDIZATION. ISO/IEC Guide 2 - Standardization and related activities - genaral vocabulary. $8 \mathrm{a}$ ed., 2004.

JUNIOR, S. B. Controles Internos como Instrumento de Governança Corporativa. Revista do BNDS, Rio de Janeiro, v.12, n.24, p.149-188, dez. 2005.

MACHADO FILHO, C. P. Responsabilidade social e governança: o debate e as implicações. São Paulo: Pioneira Thomson Learning, 2006. 172p.

McWILliAMS, A. e SIEGEL, D. Corporate social responsability: a theory of the firm perspective. The Academy of Management Review. Mississipi State, v. 26, Issue 1, p. 117-127, Jan. 2001.

MYERS, A. O valor da diversidade racial na empresas. Estudo Afro-Asiat., v. 25, n 3, p. 483-515, 2003.

SIRGY, M. J. Measuring corporate performance by building on the stakeholders model of business ethics. Journal of Business Ethics. v. 35, Issue 3, part 1, p. 143-162, feb. 2002.

SOCIAL ACCOUNTABILITY INTERNATIONAL. Disponível em: <http://www.sa-intl.org/> Acesso em: 17.05.2006.

URSINI, T. R. e SEKIGUCHI, C. Desenvolvimento sustentável e responsabilidade social: rumo à terceira geração de normas ISO. Artigo preparado para o $2^{\circ}$ volume da coleção "Uniemp Inovação - Inovação e responsabilidade social", Instituto Uniemp, São Paulo, SP. 2005. 30p. 


\section{Dados dos autores:}

Alexandre Nixon Soratto da Silva

UFSC e Inmetro - Pós-graduação em Engenharia e Gestão do Conhecimento - EGC e Departamento de Avaliação da Conformidade da Representação do Inmetro de Santa Catarina

Estudante de Doutorado e Avaliador de Acreditação

Rua Paul Harris, 250, Torre Del Plata, Estreito, Florianópolis, Santa Catarina, Brasil. 88.070-015

Telefones: (48) 99630056 e 33815211

e-mail:ansoratto@inmetro-sc.gov.br

Antônio Augusto Morini

UFSC

Pós-graduação em Engenharia e Gestão do Conhecimento - EGC

Estudante de Doutorado

Curitiba, Paraná, Brasil

Telefones: (41) 99462795

e-mail:morini@cwb.matrix.com.br

Márcia Andréia S. Almeida

Inmetro

Divisão de Orientação e Incentivo à Qualidade - DIVIQ

Instrutora em educação para o consumo

Rio de Janeiro, Rio de Janeiro, Brasil

Telefones: (21) 81041144

e-mail:msalmeida@inmetro.gov.Br

Patrícia de Souza Knabben

Faculdade Estácio de Sá

Graduação em Direito

Graduanda do Curso de Direito

Estreito, Florianópolis, Santa Catarina, Brasil

Telefones: (48) 88122523

e-mail:patisk@gamil.com 
Gregorio Varvakis

UFSC

Pós-graduação em Engenharia e Gestão do Conhecimento - EGC

Professor do EGC

Lagoa da Conceição, Florianópolis, Santa Catarina, Brasil

Telefones: (48) 33313074

e-mail:grego@egc.ufsc.br

Recebido para publicação em: 28/10/2006

Aceito para publicação em: 27/11/2006 